NASA/TM-2003-212452

\title{
Spatial Analysis of Great Lakes Regional Icing Cloud Liquid Water Content
}

Charles C. Ryerson, George G. Koenig, Rae A. Melloh, and Debra A. Meese Cold Regions Research \& Engineering Laboratory, Hanover, New Hampshire

Andrew L. Reehorst and Dean R. Miller

Glenn Research Center, Cleveland, Ohio 
Since its founding, NASA has been dedicated to the advancement of aeronautics and space science. The NASA Scientific and Technical Information (STI) Program Office plays a key part in helping NASA maintain this important role.

The NASA STI Program Office is operated by Langley Research Center, the Lead Center for NASA's scientific and technical information. The NASA STI Program Office provides access to the NASA STI Database, the largest collection of aeronautical and space science STI in the world. The Program Office is also NASA's institutional mechanism for disseminating the results of its research and development activities. These results are published by NASA in the NASA STI Report Series, which includes the following report types:

- $\quad$ TECHNICAL PUBLICATION. Reports of completed research or a major significant phase of research that present the results of NASA programs and include extensive data or theoretical analysis. Includes compilations of significant scientific and technical data and information deemed to be of continuing reference value. NASA's counterpart of peerreviewed formal professional papers but has less stringent limitations on manuscript length and extent of graphic presentations.

- TECHNICAL MEMORANDUM. Scientific and technical findings that are preliminary or of specialized interest, e.g., quick release reports, working papers, and bibliographies that contain minimal annotation. Does not contain extensive analysis.

- CONTRACTOR REPORT. Scientific and technical findings by NASA-sponsored contractors and grantees.
- CONFERENCE PUBLICATION. Collected papers from scientific and technical conferences, symposia, seminars, or other meetings sponsored or cosponsored by NASA.

- SPECIAL PUBLICATION. Scientific, technical, or historical information from NASA programs, projects, and missions, often concerned with subjects having substantial public interest.

- TECHNICAL TRANSLATION. Englishlanguage translations of foreign scientific and technical material pertinent to NASA's mission.

Specialized services that complement the STI Program Office's diverse offerings include creating custom thesauri, building customized databases, organizing and publishing research results ... even providing videos.

For more information about the NASA STI Program Office, see the following:

- Access the NASA STI Program Home Page at http://www.sti.nasa.gov

- E-mail your question via the Internet to help@sti.nasa.gov

- Fax your question to the NASA Access Help Desk at 301-621-0134

- Telephone the NASA Access Help Desk at 301-621-0390

- Write to:

NASA Access Help Desk

NASA Center for AeroSpace Information 7121 Standard Drive

Hanover, MD 21076 
NASA/TM-2003-212452

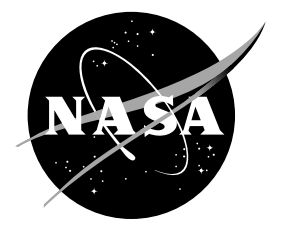

\section{Spatial Analysis of Great Lakes Regional Icing Cloud Liquid Water Content}

Charles C. Ryerson, George G. Koenig, Rae A. Melloh, and Debra A. Meese Cold Regions Research \& Engineering Laboratory, Hanover, New Hampshire

Andrew L. Reehorst and Dean R. Miller

Glenn Research Center, Cleveland, Ohio

Prepared for the

39th Aerospace Sciences Meeting and Exhibit

sponsored by the American Institute of Aeronautics and Astronautics

Reno, Nevada, January 8-11, 2001

National Aeronautics and

Space Administration

Glenn Research Center 


\section{Acknowledgments}

The authors thank the crew of NASA's Twin Otter research aircraft for providing data and technical assistance. They also thank L. Raymond of CRREL for graphics assistance and L. Peck of CRREL and F. Scott of Sensor Concepts and Applications, Inc., for thoughtful technical reviews of this paper. NASA support for this project originated from the Aerospace Operations Systems Program and was managed by the NASA Glenn Research

Center (see http:/ /icebox.grc.nasa.gov/RemoteSensing/Start.html). Army support was from ERDC/CRREL AT24 Work Item 006KDI-Characterize Inflight Icing Conditions. The views expressed are those of the authors and do not necessarily represent the official policy or position of the U.S. Government.

The Propulsion and Power Program at NASA Glenn Research Center sponsored this work.

Available from

NASA Center for Aerospace Information 7121 Standard Drive

Hanover, MD 21076
National Technical Information Service 5285 Port Royal Road Springfield, VA 22100 


\title{
Spatial Analysis of Great Lakes Regional Icing Cloud Liquid Water Content
}

\author{
Charles C. Ryerson, George G. Koenig, Rae A. Melloh, and Debra A. Meese \\ Cold Regions Research and Engineering Laboratory \\ Hanover, New Hampshire 03755 \\ Andrew L. Reehorst and Dean R. Miller \\ National Aeronautics and Space Administration \\ Glenn Research Center \\ Cleveland, Ohio 44135
}

\begin{abstract}
$\underline{\text { Abstract }}$
Clustering of cloud microphysical conditions, such as liquid water content (LWC) and drop size, can affect the rate and shape of ice accretion and the airworthiness of aircraft. Clustering may also degrade the accuracy of cloud LWC measurements from radars and microwave radiometers being developed by the government for remotely mapping icing conditions ahead of aircraft in flight. This paper evaluates spatial clustering of LWC in icing clouds using measurements collected during NASA research flights in the Great Lakes region. We used graphical and analytical approaches to describe clustering. The analytical approach involves determining the "average size" of clusters and computing a clustering intensity parameter. We analyzed flight data composed of 1-s-frequency LWC measurements for 12 periods ranging from 17.4 minutes $(73 \mathrm{~km})$ to 45.3 minutes $(190 \mathrm{~km})$ in duration. Graphically some flight segments showed evidence of consistency with regard to clustering patterns. Cluster intensity varied from 0.06 , indicating little clustering, to a high of 2.42. Cluster lengths ranged from 0.1 minutes $(0.6 \mathrm{~km})$ to 4.1 minutes $(17.3 \mathrm{~km})$. Additional analyses will allow us to determine if clustering climatologies can be developed to characterize cluster conditions by region, time period, or weather condition.
\end{abstract}

\section{Introduction}

The National Aeronautics and Space Administration (NASA), the Federal Aviation Administration (FAA) Aviation Weather Research Program, and the Army Engineer Research and Development Center/Cold Regions Research and Engineering Laboratory (ERDC/CRREL) are assessing and developing radar and microwave radiometer technologies for remotely mapping icing conditions ahead of aircraft in flight. These systems are intended to increase aviation safety and utility by enabling aircraft to avoid potentially hazardous inflight icing conditions. Establishing specifications for such systems requires consideration of limitations imposed by the operational environment, by the radar and microwave radiometer tech- nologies, and by meteorological conditions. Understanding both the range and the variability of icing cloud microphysical parameters is critical for assessing radar and radiometer remote sensing performance and for establishing specifications for the instruments. Examination of the variability of icing cloud liquid water content (LWC) with clustering theory is the thrust of this paper.

\section{Background}

Clustering of cloud microphysical properties refers to clumping, or patchiness, in the spatial distribution of cloud microphysical parameters. Clustering implies that consecutive values of LWC will be correlated over some distance, defined as the spatial coherence length. If the mean of the entire data series is used to define clustering, then within a cluster, all the LWC values will tend to be greater than the mean or all values will tend to be less than the mean. Unlike a Poisson spatial distribution, where the parameters in the series are independent, in a clustered data series the values are not independent.

Clustering of cloud microphysical properties may affect the design and accuracy of airborne or ground-based remote sensing systems designed to map icing conditions ahead of an aircraft. For example, experiments with multiple-wavelength radar to retrieve cloud $\mathrm{LWC}^{1-3}$ have shown that clustering can degrade the quality of LWC retrievals and can even cause reporting of negative LWCs. If explicit detection of LWC clusters is necessary to enhance safety, shorter radar range gates may be required. Regardless, it will be necessary for radars to operate successfully in the presence of clusters. Within clustering conditions it may be desirable to also extend radar range to provide more advanced warning. Clustering may also affect the range, especially of shorter wavelength radars, because of the likely attenuation problems within clusters.

It is not clear how radiometers will be affected by clustering of cloud microphysical parameters. Radiometers measure integrated brightness temperature and, being passive instruments, are not range-gated. As a result, ra- 
diometers probably cannot detect clustering but also may not be affected by clustering. However, the ultimate range that a radiometer can "see" into clouds is a function of cloud attenuation caused by LWC, which could be affected by clustering.

LWC and droplet size clustering can affect the rate and, as importantly, the shape of ice that forms on airfoils of fixed-wing aircraft. Aircraft traversing portions of cloud with small droplets and lower LWC in cold temperatures generally accrete rime ice. However, if extended clusters of higher LWC are intercepted, then clear ice may form with ice shapes, such as horns, that reduce lift, increase drag, and decrease control authority. This transition from rime to clear, or the reverse if LWC decreases, is a function of the Schumann-Ludlam limit, which describes changes in LWC, drop size, and temperature magnitudes required to change the type, the density, and thus the shape of ice that forms on an airfoil. ${ }^{4-6}$ Assessment of aircraft performance using models or icing wind tunnels simulating non-clustered clouds may suggest that aircraft performance is acceptable when, in actuality, conditions may be hazardous if the same average cloud LWC were clustered.

Though important, the clustering of cloud microphysical parameters has not received as much attention as have other elements of cloud microphysics. Cooper et al. ${ }^{7}$ summarized exceedance of LWC thresholds by season in California, Montana, Florida, Utah, Illinois, Kansas, and the Great Lakes region. Though not a true cluster analysis, the work indicates encounter distances and thus the maximum distance over which certain LWC magnitudes were observed. Cober et al. ${ }^{8}$, using a similar procedure, describe the patchiness of supercooled liquid water encountered in the Canadian Atlantic Storms Project (CASP) using histograms of encounter number versus duration for patches of LWC greater than $0.025 \mathrm{~g} \mathrm{~m}^{-3}$.

A considerable amount of research has addressed the fluctuations of droplet size and LWC at small scales within clouds to assess turbulence, cloud evolution, and the radiative properties of clouds ${ }^{9-12}$. However, at the cloud scale of interest to us, the most appropriate analytical methods are presented by Jameson and Kostinski, in a series of papers beginning in $1997^{4,13}$. They describe clustering of drop sizes in rainfall and clouds using coher- ence length and a cluster parameter. The most recent paper $^{4}$ describes application of their techniques to LWC in synthetically generated icing clouds. This series of papers is most applicable to our clustering problem, and it strongly influenced the work presented in this paper.

\section{Methodology}

We selected two techniques for assessing clusteringone graphical and one analytical. The intent of the graphical technique is to allow visualization of the variability of the LWC along the flight path for specified LWC values. The intent of the analytical method is to allow quantification of clustering and, perhaps, development of cluster pattern climatologies. These climatologies may be later inverted to develop correlated time series of LWC characteristics of specific cloud dynamics, such as overrunning along a warm front.

\section{Graphical Technique}

Graphically we used an incremented threshold approach to show the frequency and percentage of time during a flight transect through a cloud when LWC exceeds specific threshold values. Higher frequencies of LWC crossings from below the threshold to above the threshold suggest more LWC variability at the specified threshold value along the flight track. If the threshold chosen coincides with the Schumann-Ludlam limit, then the frequency and duration of potentially dangerous icing conditions are identified. Jameson and Kostinski ${ }^{4}$ suggest that more dangerous icing conditions can occur when an aircraft is flying in and out of areas that exceed the Schumann-Ludlam limit than when the aircraft is flying in an area that is Poissonian and does not exceed the Schumann-Ludlam limit for extended periods.

For example, Figure 1 shows a small portion of a synthetically generated flight series with LWC values occurring at 1-s intervals generated from a random series with no clustering. Incremented LWC thresholds at $0.02-\mathrm{g} \mathrm{m}^{-3}$ intervals from the same data yielded a plot (Fig. 2) with a linear decrease in percentage of time greater than the threshold as the threshold increases. The number of crossings increases from zero at a threshold smaller than the minimum LWC, to a maximum at the mean LWC for the data series, to zero again when the threshold be-

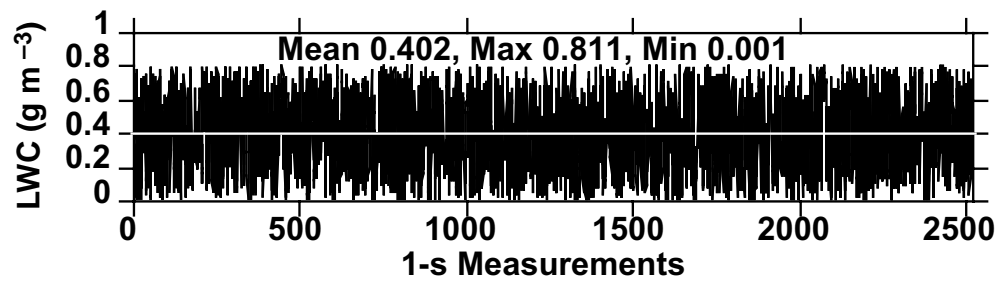

Figure 1. Synthetic random series with no clustering. The white line represents the mean of the data series. 


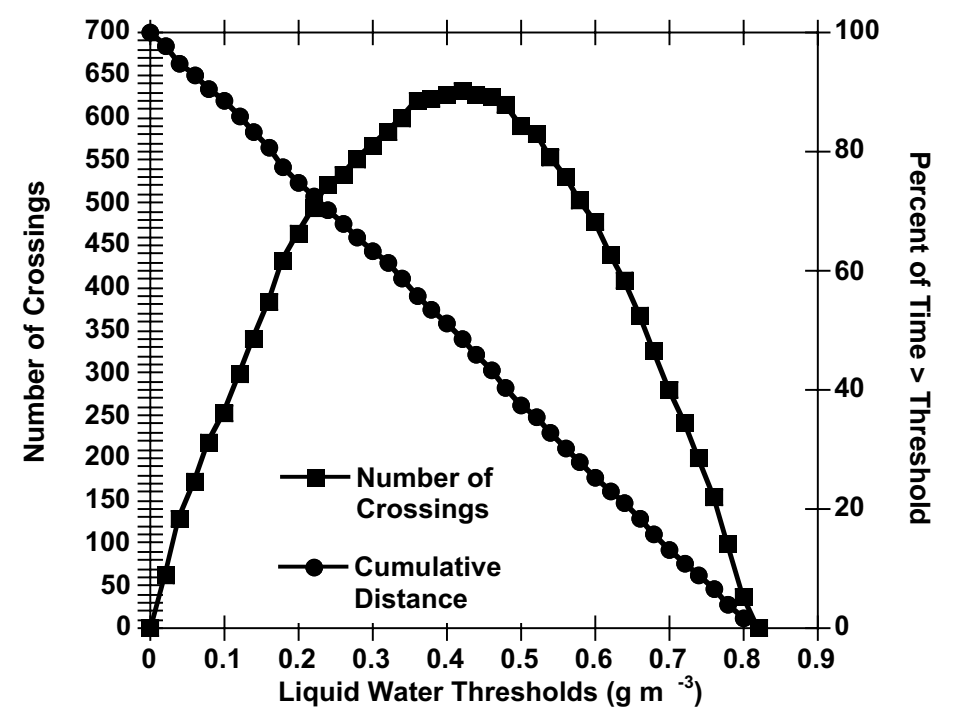

Figure 2. Cumulative distance and number of crossings of LWC greater than thresholds for nonclustered, Poissonian random series.

comes larger than the maximum LWC in the series. The linear decrease of percentage of time exceeded by the thresholds as the threshold value increases, and the symmetry of the number of crossings about the mean LWC, is a result of the randomness and lack of clustering of the series (Fig. 2). As illustrated later, flight segments of actual cloud LWC clusters show different percentages of time greater than the threshold and different crossing frequency relationships.

\section{Analytical Technique}

We utilize the methodology of Jameson and Kostinski ${ }^{4}$ to analytically describe LWC clustering. If the cloud LWC is not clustered, it is Poissonian. The first step in the analytical approach involves determining if clustering occurs in the data series. Kostinski and Jameson ${ }^{13}$ indicate that a two-point autocorrelation function, as given in equation 1 , can be used to determine the presence of clustering:

$$
\eta(l)=\frac{\left[\overline{k(l) k(0)}-\mu^{2}\right]}{\mu^{2}}
$$

where $\eta(l)=$ two-point autocorrelation function

$$
\mu=\text { mean of the series }
$$

$k(l)$ and $k(0)=$ values at the reference location (time) and distance (time), respectively, at a distance (seconds) $l$ from the reference.

If clustering does not occur, that is, all values in the series are statistically independent, or Poissonian, the mean of the series equals the variance $\left[\overline{k(l) k(0)}=\mu^{2}\right]$ and $\eta(l)$ is
equal to zero.

The second step is to specify the "average size" of the clusters. The "average" cluster size, defined as the coherence length, is the length at which the autocovariance equals $1 / e$, where $e$ is the base of the natural logarithm and $1 / e=0.3679$. The autocovariance is defined as

$$
C_{D}(l)=\frac{\left[\overline{k(l) k(0)}-\mu^{2}\right]}{\sigma^{2}}
$$

where $\sigma^{2}$ is the variance for the data series.

The first step determines the presence of clustering, and the second step determines the coherence length or the "average size" of the clusters. In the final step, a clustering intensity parameter is determined as suggested by Jameson and Kostinski ${ }^{4}$, defined as:

$$
\aleph=\eta(0)\left(1-\frac{\mu}{\sigma^{2}}\right) \text {. }
$$

The clustering intensity parameter depends on the value of the two-point autocorrelation function at zero lag length and the mean and variance associated with the data series. The clustering intensity provides insight into the magnitude of the values associated with clustering relative to the mean (see ref. 4, Figure 4). In a Poisson distribution, where clustering does not occur, the clustering intensity is zero. This is because, in a Poisson distribution, the mean equals the variance, so the last term in equation 3 will equal one, making the corresponding clustering intensity zero. The clustering intensity increases as the variance increases relative to the mean for a given value of the two-point autocorrelation function. Two data series can have the same mean, but the series that contains values that differ the most from the mean will have the greatest clustering intensity. 
Inflight Measurements

Liquid water measurements were made by the NASA Glenn Research Center's Twin Otter research aircraft during the Supercooled Large Droplet Research Program $(\mathrm{SLDRP})^{14}$, conducted from the winter of 1996-97 to December 1999. The flight program was a joint effort between NASA, the National Center for Atmospheric Research (NCAR), and the FAA. The primary objective of the program was to acquire flight research data on supercooled large droplets (SLDs, defined as larger than $50 \mu \mathrm{m}$ in diameter) for characterization of the SLD environment aloft.

Based on weather forecasts and real-time inflight guidance provided by NCAR, the NASA Glenn Icing Research Aircraft was flown from the NASA Glenn Research Center to locations where conditions were believed to be conducive to the formation of SLDs aloft. Research flights were conducted over regions adjacent to Lake Erie and Lake Michigan, extending as far south as Parkersburg, West Virginia. Onboard instrumentation was used to record meteorological characteristics encountered during the flight ${ }^{14}$. Though SLD conditions were often located, icing conditions with cloud-size droplets less than $50 \mu \mathrm{m}$ in diameter and mixed phase conditions were encountered as well. This occurred often when in transit to or from an area with forecasted SLDs.

Liquid water content values used in this study were measured by the Twin Otter with a CSIRO-King hot-wire probe mounted on the fuselage upstream of the windshield, with a range of $0-1.0 \mathrm{~g} \mathrm{~m}^{-3}$. The probe is sampled at 10 $\mathrm{Hz}$, and liquid water content is calculated for 1-s increments. Probe drift (zero offset) was adjusted by comparing the King probe mean LWC during a flight segment against a Forward Scattering Spectrometer Probe (FSSP) mean LWC for the same period. The King probe zerooffset was adjusted to allow the King and FSSP mean LWCs to match as closely as possible while maintaining non-negative LWC values from the King probe. Probe zero-offset affects the coherence length and the clustering intensity parameter because of the relationship with the mean LWC (eq 1-3).

NASA provided CRREL with LWC measurements for 32 flights during the winters of 1996-97 and 1997-98. Dependence of LWC variability on height above the cloud base (or below the cloud top), temperature, presence or absence of ice crystals, and turbulence ${ }^{15}$ led us to seek flight segments that, as much as possible, occurred at a nearly constant altitude. In addition, we sought segments that were along a nearly constant heading, though we often accepted flights of changing direction if they did not double back on themselves. For this study we chose to ignore the effects of temperature and ice crystal variation, which could partially control clustering. We had insufficient information to exclude turbulence effects.

All 32 NASA flights were plotted to show the location of LWC with regard to flight altitude and heading. We chose 12 flight segments for analysis because they had no breaks in liquid water content and were at nearly constant elevation and heading. We also chose long segments to represent clustering conditions as faithfully as possible. The characteristics of each selected flight segment are listed in Table 1. Flight segment durations ranged from 17.4 minutes $(73 \mathrm{~km})$ to 45.3 minutes $(190 \mathrm{~km})$, and mean LWCs ranged from 0.03 to $0.35 \mathrm{~g} \mathrm{~m}^{-3}$.

\section{Analysis}

As discussed in the methodology, we used a graphical threshold approach to show the frequency and percentage of time in each flight segment when the LWC exceeds specific threshold values. Figure 2, a hypothetical random series with no clustering, showed the time with values greater than the thresholds and the number of cross-

\begin{tabular}{|lccccc|}
\hline \multicolumn{5}{c}{ Table 1. Flight segment characteristics. } \\
Flight & $\begin{array}{c}\text { Duration } \\
(\mathrm{s})\end{array}$ & $\begin{array}{c}\text { LWC mean } \\
\left(\mathrm{g} \mathrm{m}^{-3}\right)\end{array}$ & $\begin{array}{c}\text { LWC variance } \\
\left(\mathrm{g} \mathrm{m}^{-3}\right)\end{array}$ & $\begin{array}{c}\text { Coherence length } \\
(\mathrm{s})\end{array}$ & $\begin{array}{c}\text { Cluster } \\
\text { parameter }\end{array}$ \\
\hline $97-01-24 \mathrm{f1b}$ & 1495 & 0.05 & 0.0006 & 55 & 0.24 \\
$97-01-24 \mathrm{f}$ a & 1141 & 0.08 & 0.014 & 80 & 2.42 \\
$97-01-24 \mathrm{f} 1 \mathrm{c}$ & 1044 & 0.14 & 0.008 & 147 & 0.41 \\
$97-03-14$ & 2520 & 0.16 & 0.34 & 247 & 1.29 \\
$98-02-04 \mathrm{a}$ & 2536 & 0.03 & 0.00006 & 8 & 0.06 \\
$98-02-04 \mathrm{~b}$ & 1353 & 0.18 & 0.0037 & 8 & 0.11 \\
$98-02-04 \mathrm{c}$ & 1156 & 0.21 & 0.0123 & 20 & 0.31 \\
$98-02-04 \mathrm{~d}$ & 1151 & 0.19 & 0.008 & 30 & 0.24 \\
$98-02-05$ & 1709 & 0.09 & 0.004 & 57 & 0.42 \\
$98-02-12$ & 2719 & 0.35 & 0.10 & 225 & 0.08 \\
$98-02-24 \mathrm{a}$ & 1161 & 0.20 & 0.015 & 149 & 0.36 \\
$98-02-24 \mathrm{~b}$ & 1809 & 0.23 & 0.008 & 25 & 0.15 \\
\hline
\end{tabular}


ings as being linear and symmetrical, respectively, with threshold magnitude. This is not the case with actual cloud measurements. The cumulative distance for all cases is nearly log-linear, rather than linear, and the number of crossings varies considerably with threshold value (Fig. 3).

Comparison of the 12 flight segment plots (not all shown here) showed no consistent relationship between cluster parameter magnitude and either frequency or percentage of time when LWC is greater than a threshold. The plots do suggest, however, that there may be a relationship between coherence length and the shape of the curve representing the number of threshold crossings with threshold magnitude. Flight segments with coherence lengths of less than $147 \mathrm{~s}(10.3 \mathrm{~km})$ all had unimodal dis- tributions (Fig. 3a), whereas flight segments with coherence lengths of $147 \mathrm{~s}$ or greater showed multi-modal distributions (Fig. 3b). In addition, the plots show evidence of physical consistency within given meteorological synoptic situations. For example, flight segments 98-02-04a$\mathrm{d}$ all occurred during one flight, and the relationships between the threshold and the frequency and percentage of time that conditions exceed thresholds are very similar for the four segments (see Figure 4 for three of the four flight segments). However, this was not true for the multiple segments of flights 98-02-24 and 97-01-24. Though the cluster parameter was low for all segments of flights 98-02-04 and 98-02-24, it varied widely in segments of flight 97-01-24. We have not analyzed sufficient flights to develop a catalogue of distinctive conditions. How-
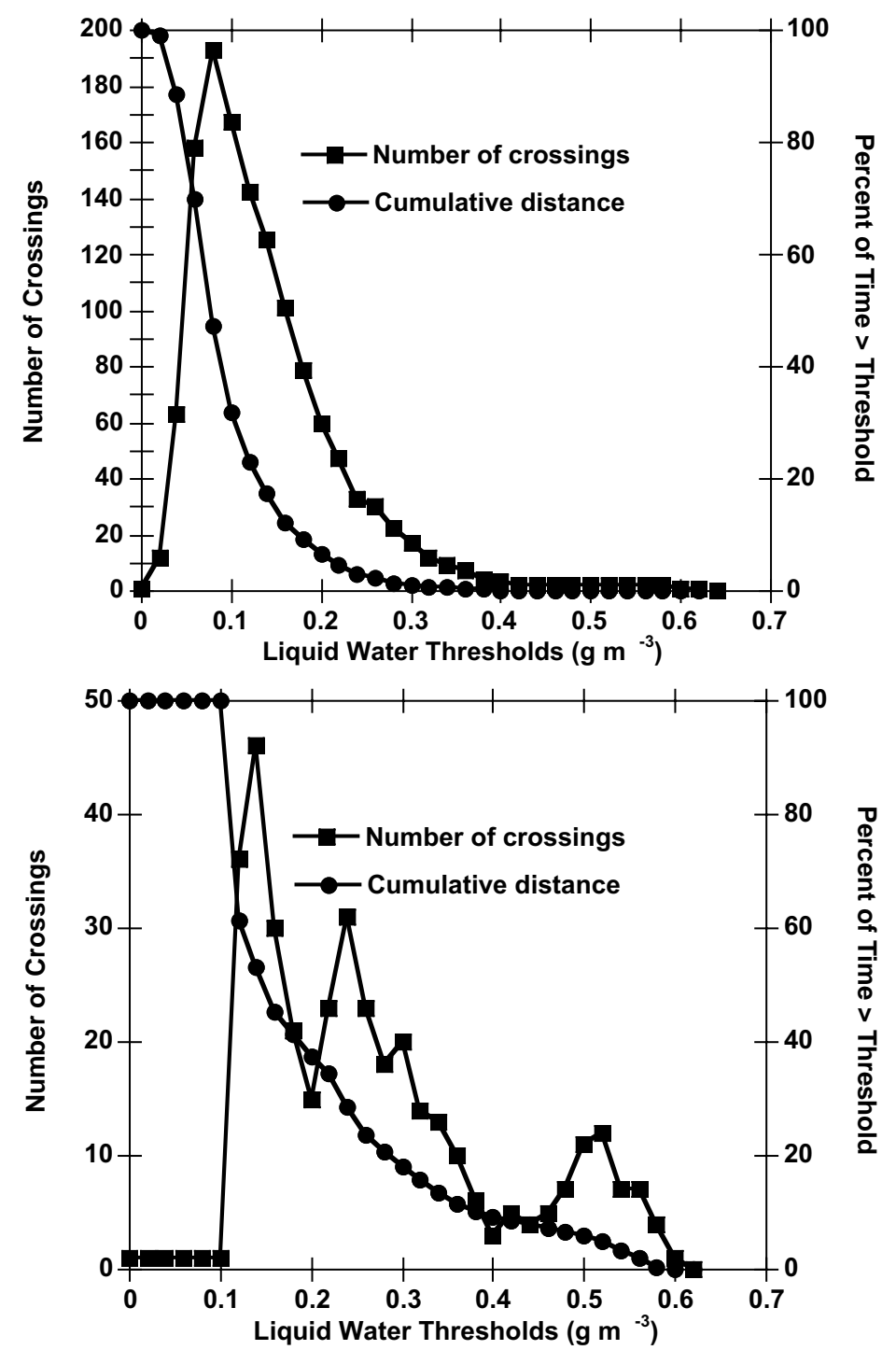

Figure 3. Flight segment 98-02-05 (top, Figure 3a) with a coherence length of $57 \mathrm{~s}$, and flight segment 98-02-24a (bottom, Figure 3b) with a coherence length of $149 \mathrm{~s}$. 

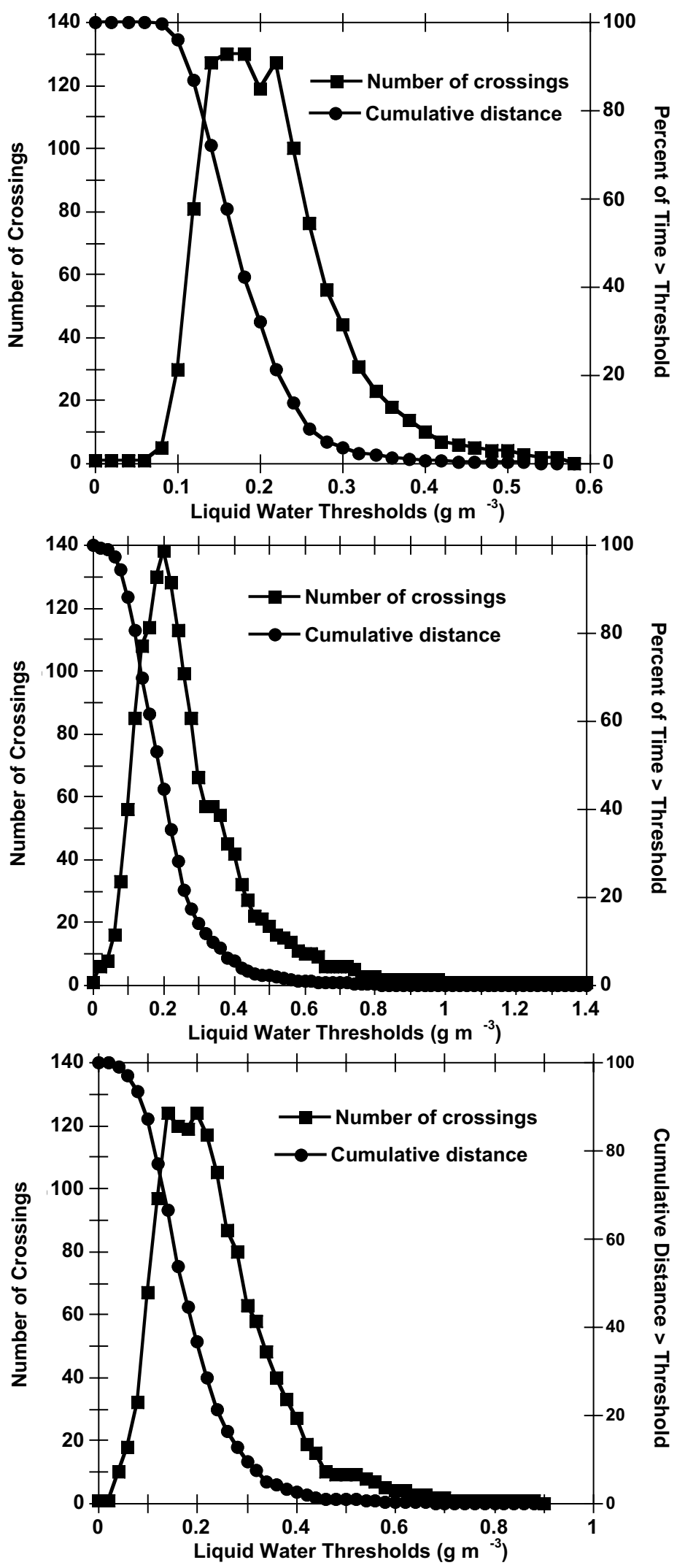

Figure 4. Flight segments 98-02-04b-d (top to bottom, respectively), all from the same flight, showing remarkably consistent crossing and cumulative distance patterns with threshold. 
ever, we believe that certain characteristics of the variability of the LWC along the flight path may be systematically determined with plots of this type.

The analytical technique indicates that the Jameson and Kostinski ${ }^{4}$ cluster parameter varies widely, from a low of 0.06 indicating almost no clustering, to a high of 2.42 (Table 1). Jameson and Kostinski ${ }^{4}$ provide an indication of cluster appearance with cluster parameter mag- nitude in their Figure 4. Our Figure 5 shows $1000 \mathrm{~s}$ of four flight segments covering the range of cluster magnitudes computed for our 12 flight segments. They compare well to Jameson and Kostinski's example, and they indicate that there is a relationship between cluster parameter and the graphical appearance of clustering.

The coherence length, as shown in Table 1, is measured as time in seconds and represents the typical size of
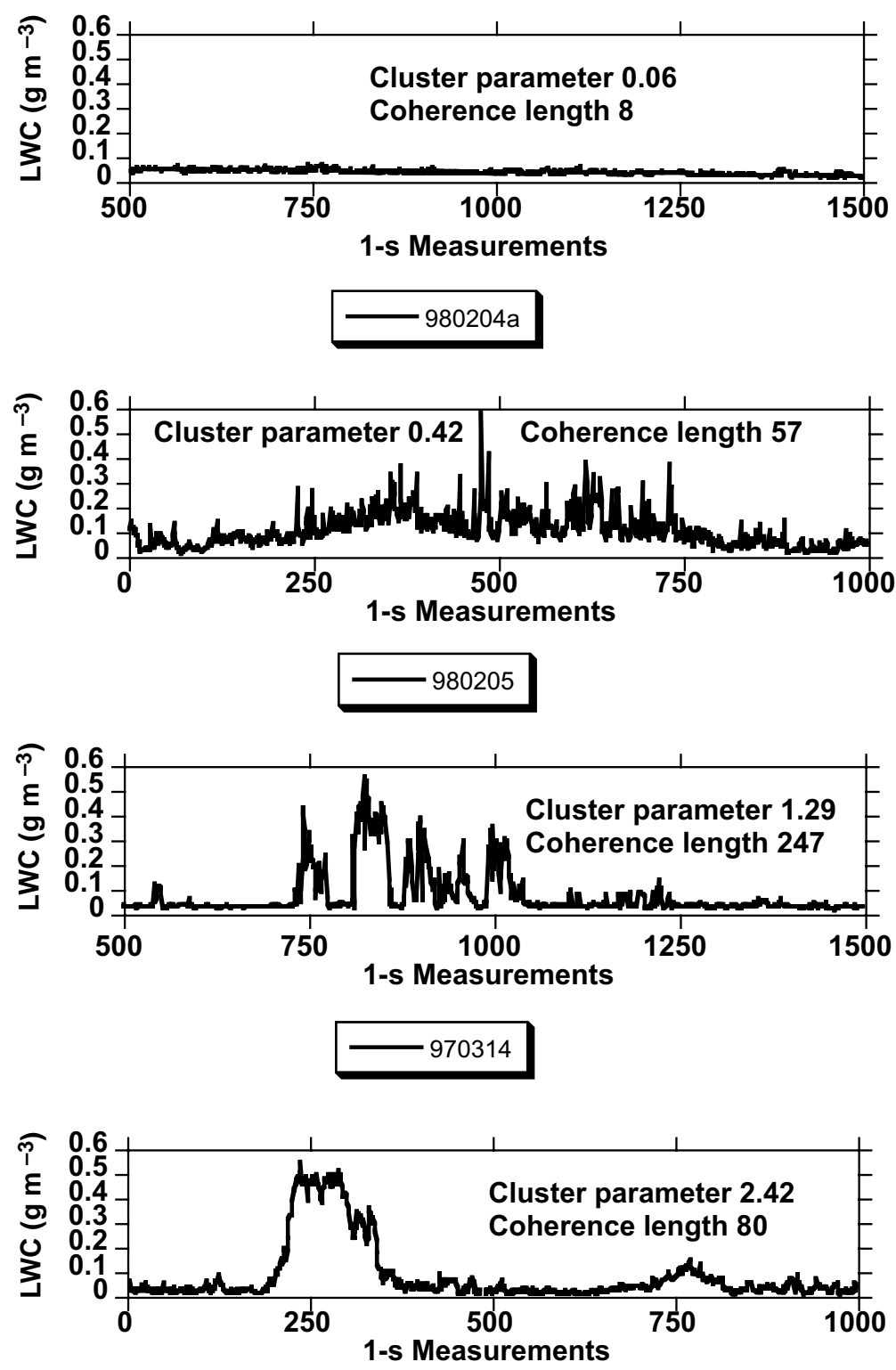

\section{$970124 \mathrm{f} 2 \mathrm{a}$}

Figure 5. From top to bottom, flight segments 98-02-04a, 98-02-05, 9703-14, and 97-01-24f2a, showing increasing visual clustering as cluster parameter increases. The $x$ and $y$ scales on all plots are the same for comparative purposes. 


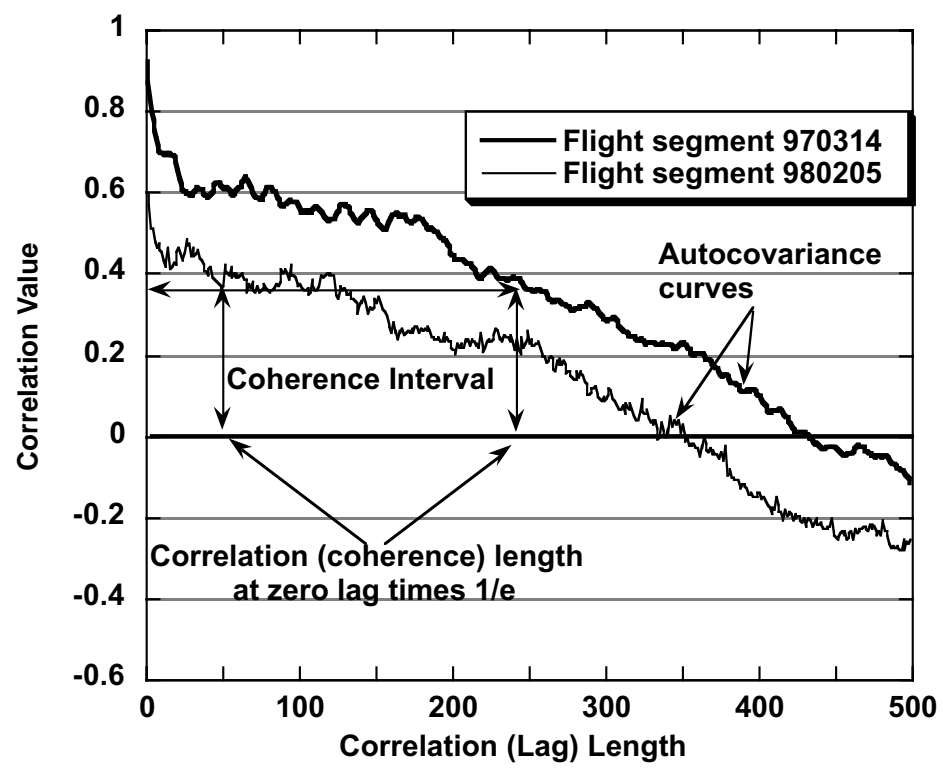

Figure 6. Demonstration of coherence length computation along autocovariance curves for two flight segments.

clusters. Figure 6 illustrates how the coherence length was computed from the 1/e distance along the autocovariance curve for two flights. Considering the average Twin Otter flight speed of about $70 \mathrm{~m} \mathrm{~s}^{-1}$, clusters during the 12 flight segments ranged from about $560 \mathrm{~m}$ to $17.3 \mathrm{~km}$ in length. Figure 5 also suggests that there is a relationship between coherence length and the visual appearance of cluster size.

\section{Discussion}

Jameson and Kostinski ${ }^{4}$ analyzed LWC in icing conditions using a simulated series of cloud measurements. Based on our small sample size of 12 flight segments from only 7 of the 32 NASA SLDRP flights, our analyses indicate that clustering of actual cloud LWC varies over a wide range of cluster intensities and coherence lengths. Our largest cluster intensity-2.42-exceeds the largest value illustrated in Jameson and Kostinski's Figure 42.0 - though they do not provide a maximum cluster value for natural conditions.

We found the cluster intensity to vary over a wide range among flights and occasionally among discontinuous segments within the same flight. The graphical analyses and analytical results show considerable consistency between segments of the 98-02-04 flight. This suggests that the atmospheric dynamics controlling the clustering persisted for a considerable time and distance. Only analyses of more flight segments will allow us to judge this better. Since one of our goals is to determine if cluster climatologies, or characterizations, can be developed for regions, for time periods, or for meteorological conditions such as warm front overrunning or cold air advec- tion over water, a large sample of measurements will be required to adequately characterize the range of cluster conditions and their variance.

NASA SLDRP flights were intended to locate SLDs, so all flights were made into conditions where weather forecasters assessed SLDs as a possibility. However, since large portions of some flights were made in transit, many analyses include non-SLD conditions. We have not assessed whether SLDs were present in the 12 flight segments analyzed, nor have we assessed the meteorological conditions documented by NASA and NCAR for the flights encountering SLDs. The SLD and meteorological information may provide further guidance for explaining variation in clustering among flight segments.

Other factors that may affect clustering intensities and coherence lengths include the position of the aircraft with respect to the height above the cloud base, the direction of aircraft movement with regard to any lineation within the cloud structure, turbulence, temperature, and fluctuations in glaciation from cloud to cloud. We will assess some of these factors from available information as we analyze additional flight segments to attempt to explain segment-to-segment variance.

Though the graphical presentations of frequency and duration above thresholds have value in the analyses, we have yet to learn how to use them fully. However, the clustering intensities developed from Jameson and Kostinski's ${ }^{4}$ methodology, as well as coherence lengths, have great value in analytically assessing clustering. Meteorological synoptic conditions, region, and season are likely to affect cloud clustering characteristics, but the 
extent is not known. However, we believe that climatological characterizations of cloud microphysical conditions can be constructed, using the methodologies demonstrated in this paper, to represent the clustering of liquid water content, drop and particle size distributions, and glaciation. These climatologies could then be used to assess aircraft icing conditions and the potential performance of icing remote sensing systems synoptically, regionally, and seasonally.

Inversion of cluster parameter and correlation length, for an assumed LWC distribution for the clustered conditions, would generate a correlated data series for use by modelers assessing icing remote sensing system performance and specifications. Sensitivity analyses could be performed by varying coherence lengths, and clustering intensities, to generate a spectrum of correlated data series that reflect natural conditions. These series could be used to investigate the impact of clustered conditions on aircraft icing and on radar and microwave radiometer systems being proposed for remote detection of aircraft icing conditions.

Though our analyses are of conditions found in one of the most icing-intensive areas of North America ${ }^{16,17}$, the NASA measurements represent only that one region. Previous programs assessing icing cloud microphysics, such as the Winter Icing and Storms Project (WISP), conducted by NCAR in the Front Range area of Colorado ${ }^{18}$, may show considerably different clustering conditions. It is likely that clustering conditions vary significantly from region to region, just as other icing cloud parameters $\mathrm{do}^{7}$. This paper is a demonstration of the problem as it addresses remote sensing needs.

\section{Conclusions}

Cloud cluster analysis is an element of cloud microphysics that has not received much attention. Clouds are neither temporally static or uniform nor spatially uniform. However, the difficulty is how to measure and quantify variation. Methodologies presented here may be useful for assessing clustering for our remote sensing applications.

In addition to the examples presented here, we will assess more cases from the NASA SLDRP, from the NCAR Winter and Icing Storms Project (WISP), and from the Mt. Washington Icing Sensors Project (MWISP) ${ }^{19}$, and as resources permit, we will examine other parameters such as drop size, temperature, particle concentration, and glaciation. It may ultimately be useful to assess vertical fluctuations of microphysical conditions within clouds, a problem more difficult than horizontal variation because of the difficulty of acquiring vertical measurements of cloud microphysical properties and the potential for greater variation than observed in the horizontal.

It is likely that most icing clouds, especially those with more dangerous conditions, are typically "patchy" and rarely Poissonian. Clustering of cloud microphysical parameters affects icing processes and potentially the ability of remote sensing systems to identify icing conditions. Clustering quantification, and perhaps creation of representative data series inverted from climatological summaries of clustering, will allow more accurate modeling of icing and remote sensing systems. CRREL, NASA, and the FAA are quantifying clustering of NASA SLDRP flights and developing inversion techniques for these purposes.

\section{References}

1. Martner, B., R. Kropfli, L. Ash, and J. Snider, 1993, "Cloud liquid water content measurement tests using dual wavelength radar." NOAA Technical Memorandum ERL ETL-235.

2. Martner, B., R. Kropfli, L. Ash, and J. Snider, 1991, "Progress report on analysis of differential attenuation radar obtained during WISP-91." NOAA Technical Memorandum ERL WPL-215.0

3. Mead, J., A. Pazmany, and M. Goodberlet, 1998, "Evaluation of technologies for the design of a prototype in-flight remote aircraft icing potential detection system." DOT/FAA/AR-98/72 report. Technical Memorandum 102456.

4. Jameson, A.R, and A.B. Kostinski, 2000, "The effect of stochastic cloud structure on the icing process" Journal of Applied Meteorology, 57, 2883-2891.

5. Ludlam, F., 1958, “The hail problem." Nubila, 1, 12 96.

6. Olsen, W., and E. Walker, 1986, "Experimental evidence for modifying the current physical model for ice accretion on aircraft surfaces." NASA Technical Memorandum 87184.

7. Cooper, W., M. Politovich, and W. Sand, 1982, "Nature of icing conditions encountered during meteorological research." Unpublished contract report. Martin, Pringle, Oliver, Triplett and Wallace, Wichita, Kansas. 
8. Cober, S., G. Isaac, and J. Strapp, 1995, “Aircraft icing measurements in east coast winter storms." Journal of Applied Meteorology, 34: 88-100.

9. Davis, A., A. Marshak, H. Gerber, and W. Wiscombe, 1999, "Horizontal structure of marine boundary layer clouds from centimeter to kilometer scales." Journal of Geophysical Research, 104, No. D6, 6123-6144.

10. Cahalan, R., and J. Joseph, 1989, "Fractal statistics of cloud fields." Monthly Weather Review, 117, 261-272.

11. Joseph, J., and R. Cahalan, 1990, "Nearest-neighbor spacing in fair weather cumulus." Journal of Applied Meteorology, 29, 793-805.

12. Malinowski, S., M. Leclerc, and D. Baumgardner, 1994, "Fractal analysis of high-resolution cloud droplet measurements." Journal of the Atmospheric Sciences, 51, 397-413.

13. Kostinski, A.B., and A.R. Jameson, 1997, "Fluctuation properties of precipitation. Part I: On deviation of single-size drop counts from the Poisson distribution." Journal of the Atmospheric Sciences, 54, 21742186.

14. Miller, D., T. Ratvasky, B. Bernstein, F. McDonough, and J. Strapp, 1998, "NASA/FAA/NCAR Supercooled large droplet icing flight research: Summary of winter 96-97 flight operations." NASA/TM-1998-206620, AIAA-98-0577.
15. Politovich, M., 1999, "How can we use and depict variability of clouds in icing forecasts?" In Proceedings of the $8^{\text {th }}$ Conference on Aviation, Range and Aerospace Meteorology, Dallas, 10-15 January, 443-446.

16. Bernstein, B.C., and B.G. Brown, 1997, "A climatology of supercooled large drop conditions based upon surface observations and pilot reports of icing." In Proceedings, $7^{\text {th }}$ Conference on Aviation, Range and Aerospace Meteorology, Long Beach, California, paper 2D7, February, 82-87.

17. Strapp, J., R. Stuart, and G. Isaac, 1996, “A Canadian climatology of freezing precipitation, and a detailed study using data from St. Johns, Newfoundland." In Proceedings of the FAA International Conference on Aircraft Inflight Icing, Vol. II. Working Group Papers, Final Report, 45-55.

18. Rasmussen, R., M. Politovich, J. Marwitz, W. Sand, J. McGinley, J. Smart, R. Pielke, S. Rutledge, D. Wesley, G. Stossmeister, B. Bernstein, K. Elmore, N. Powell, E. Westwater, B. Boba Stankov, and D. Burrows, 1992, "Winter Icing and Storms Project (WISP)." Bulletin of the American Meteorological Society, 73, 951-974.

19. Ryerson, C., M. Politovich, K. Rancourt, G. Koenig, R. Reinking, D. Miller, 2000, “Overview of Mt. Washington Icing Sensors Project." American Institute of Aeronautics and Astronautics, ERDC/CRREL MP-OO5455 . 

Public reporting burden for this collection of information is estimated to average 1 hour per response, including the time for reviewing instructions, searching existing data sources, gathering and maintaining the data needed, and completing and reviewing the collection of information. Send comments regarding this burden estimate or any other aspect of this collection of information, including suggestions for reducing this burden, to Washington Headquarters Services, Directorate for Information Operations and Reports, 1215 Jefferson Davis Highway, Suite 1204, Arlington, VA 22202-4302, and to the Office of Management and Budget, Paperwork Reduction Project (0704-0188), Washington, DC 20503.

\begin{tabular}{|l|l|l|}
\hline 1. AGENCY USE ONLY (Leave blank) & $\begin{array}{c}\text { 2. REPORT DATE } \\
\text { July } 2003\end{array}$ & $\begin{array}{r}\text { 3. REPORT TYPE AND DATES COVERED } \\
\text { Technical Memorandum }\end{array}$ \\
\hline
\end{tabular}

\section{TITLE AND SUBTITLE} 5. FUNDING NUMBERS

Spatial Analysis of Great Lakes Regional Icing Cloud Liquid Water Content

\section{AUTHOR(S)}

Charles C. Ryerson, George G. Koenig, Rae A. Melloh, Debra A. Meese, Andrew L. Reehorst, and Dean R. Miller

\section{PERFORMING ORGANIZATION NAME(S) AND ADDRESS(ES)}

National Aeronautics and Space Administration

John H. Glenn Research Center at Lewis Field

Cleveland, Ohio 44135-3191
WBS-22-708-20-06

8. PERFORMING ORGANIZATION REPORT NUMBER

E-13994

\section{SPONSORING/MONITORING AGENCY NAME(S) AND ADDRESS(ES)}

National Aeronautics and Space Administration

Washington, DC 20546-0001

10. SPONSORING/MONITORING AGENCY REPORT NUMBER

NASA TM-2003-212452

AIAA-2001-0394

\section{SUPPLEMENTARY NOTES}

Prepared for the 39th Aerospace Sciences Meeting and Exhibit sponsored by the American Institute of Aeronautics and Astronautics, Reno, Nevada, January 8-11, 2001. Charles C. Ryerson, George G. Koenig, Rae A. Melloh, and Debra A. Meese, Cold Regions Research \& Engineering Laboratory, Hanover, New Hampshire 03755; Andrew L. Reehorst and Dean R. Miller, NASA Glenn Research Center. Responsible person, Dean R. Miller, organization code 5840, 216-433-5349.

Unclassified - Unlimited

Subject Categories: 03 and 34

Distribution: Nonstandard

Available electronically at http://gltrs.grc.nasa.gov

This publication is available from the NASA Center for AeroSpace Information, 301-621-0390.

\section{ABSTRACT (Maximum 200 words)}

Clustering of cloud microphysical conditions, such as liquid water content (LWC) and drop size, can affect the rate and shape of ice accretion and the airworthiness of aircraft. Clustering may also degrade the accuracy of cloud LWC measurements from radars and microwave radiometers being developed by the government for remotely mapping icing conditions ahead of aircraft in flight. This paper evaluates spatial clustering of LWC in icing clouds using measurements collected during NASA research flights in the Great Lakes region. We used graphical and analytical approaches to describe clustering. The analytical approach involves determining the "average size" of clusters and computing a clustering intensity parameter. We analyzed flight data composed of 1-s-frequency LWC measurements for 12 periods ranging from 17.4 minutes $(73 \mathrm{~km})$ to 45.3 minutes $(190 \mathrm{~km})$ in duration. Graphically some flight segments showed evidence of consistency with regard to clustering patterns. Cluster intensity varied from 0.06 , indicating little clustering, to a high of 2.42. Cluster lengths ranged from 0.1 minutes $(0.6 \mathrm{~km})$ to 4.1 minutes $(17.3 \mathrm{~km})$. Additional analyses will allow us to determine if clustering climatologies can be developed to characterize cluster conditions by region, time period, or weather condition.

\section{SUBJECT TERMS}

Liquid water content; LWC; Supercooled large droplet research program; SLDRP

15. NUMBER OF PAGES

16

16. PRICE CODE

\begin{tabular}{|c|c|c|}
\hline $\begin{array}{c}\text { 17. SECURITY CLASSIFICATION } \\
\text { OF REPORT } \\
\text { Unclassified }\end{array}$ & $\begin{array}{c}\text { 18. SECURITY CLASSIFICATION } \\
\text { OF THIS PAGE } \\
\text { Unclassified }\end{array}$ & $\begin{array}{c}\text { 19. SECURITY CLASSIFICATION } \\
\text { OF ABSTRACT } \\
\text { Unclassified }\end{array}$ \\
\hline
\end{tabular}

NSN 7540-01-280-5500
Standard Form 298 (Rev. 2-89)

Prescribed by ANSI Std. Z39-18 298-102 